\title{
LA CONTRIBUCIÓN DEL TRIBUNAL CONSTITUCIONAL ESPAÑOL A LA DECONSTRUCCIÓN DE LA DISCRIMINACIÓN POR RAZÓN DE SEXO
}

The contribution of the Spanish Constitutional Court in the deconstruction of discrimination for reason of sex

\author{
M. a JOSEFA RIDAURA MARTÍNEZ \\ Universidad de Valencia \\ Sefa.ridaura@uv.es
}

\author{
Cómo citar/Citation \\ Ridaura Martínez, M.a J. (2020) \\ La contribución del Tribunal Constitucional español a la \\ deconstrucción de la discriminación por razón de sexo. \\ Anuario Iberoamericano de Justicia Constitucional, 24(2), 335-364. \\ doi: https://doi.org/10.18042/cepc/aijc.24.10
}

\section{Resumen}

El presente trabajo ofrece un estudio de la doctrina del Tribunal Constitucional español relativa a la igualdad y a la prohibición de discriminación por razón de sexo. Comprende el análisis de la jurisprudencia del Tribunal desde sus primeras sentencias en 1981 — tras su puesta en funcionamiento — hasta finales de 2019, adentrándose en los numerosos pronunciamientos dictados, dada la severa realidad de la discriminación por razón de sexo a la que se ha debido enfrentar, tanto normativa como de facto. Ello nos permitirá constatar su loable aportación, tanto en la incorporación, como en la reafirmación de categorías conceptuales dirigidas a desarticular la discriminación por esta causa, en el marco de un texto constitucional que predica la igualdad de la mujer como una exigencia constitucional.

\section{Palabras clave}

Igualdad; prohibición de discriminación; derecho antidiscriminatorio; acciones positivas; discriminación positiva. 


\section{Abstract}

This paper offers a study of the Spanish Constitutional Court's doctrine on equality and the prohibition of discrimination on the basis of sex. It includes an analysis of the Court's case law from its first judgments in 1981 - after it was set up - until the end of 2019, going into the numerous pronouncements issued, given the severe reality of sex discrimination that it has had to face, both normatively and de facto. This will allow us to confirm its laudable contribution, both in the incorporation and in the reaffirmation of conceptual categories aimed at dismantling discrimination on this ground, within the framework of a constitutional text that preaches the equality of women as a constitutional requirement.

\section{Keywords}

Equality; prohibition of discrimination; anti-discrimination law; affirmative action. 


\section{SUMARIO}

I. INTRODUCCIÓN. II. LA CONFIGURACIÓN CONSTITUCIONAL DE LA IGUALDAD: 1. Las vertientes de la igualdad. 2. Igualdad versus uniformidad y el canon de constitucionalidad de las diferencias de trato. III. LA DISCRIMINACIÓN POR RAZÓN DE SEXO: 1. ¿̇Es necesario justificar que el sexo es una categoría sospechosa de la discriminación que requiere tratamientos desiguales para su reparación? 2. ¿̇ué consecuencias derivan de que el sexo sea una categoría sospechosa de la discriminación? 3. Alcance del mandato antidiscriminatorio. IV. LA INTERDICCIÓN DE DISCRIMINACIÓN: 1. Discriminación directa: 1.1. Las cláusulas de celibato. 1.2. Diferencias salariales basadas en el sexo. 1.3. Los tratos desfavorables basados en el embarazo o en la maternidad, por afectar solo a la mujer, constituyen discriminación por razón de sexo. 1.4. Acoso sexual. 1.5. La violencia de género: una atroz discriminación directa. 2. Discriminación indirecta. 3. Discriminación por asociación. 4. La multidiscriminación. 5. Medidas paternalistas falsamente protectoras. V. ERRADICAR LA DISCRIMINACIÓN MEDIANTE UN DERECHO NIVELADOR Y REPARADOR: 1. El derecho antidiscriminatorio como exigencia de la igualdad sustancial: 1.1. Las acciones positivas. 1.2. La discriminación inversa. Biblografía.

\section{INTRODUCCIÓN}

La discriminación sufrida históricamente por la mujer, y que aún sigue sufriendo hoy, por el mero hecho de ser mujer, es una de las más palmarias y dilatadas en el tiempo y en sus manifestaciones, tanto normativas como fácticas. Esta situación repugna el orden constitucional y exige la intervención de los poderes públicos en orden a la eliminación de todo vestigio de discriminación.

En este trabajo me centraré en analizar la aportación del Tribunal Constitucional español en la reparación de la discriminación por razón de sexo. Si bien haré también referencia a modelos comparados, en la medida en que muchas de las categorías dirigidas a desterrar la desigualdad y reparar la discriminación son obra de tribunales, tanto nacionales como internacionales. Y es que, a la luz de la compleja configuración de la igualdad en el constitucionalismo actual, se ha ido tejiendo toda una rica construcción jurisprudencial que, en virtud de las «traslaciones de estructuras conceptuales autónomas» (Solozábal, 1998: 155), han ido fluyendo y calando, después, en muchos ordenamientos; de forma que hoy en día contamos con ciertas categorías que conforman una especie de ius comune aplicable a todos aquellos Estados que confieren a la igualdad y a la prohibición de discriminación un 
lugar central. Ciertamente, la mayoría de dichas medidas, dirigidas tanto a asegurar la igualdad como las denominadas de derecho antidiscriminatorio, son de construcción pretoriana, pues nacen, en buena medida, gracias a un cierto activismo judicial, constituyendo sus decisiones un vehículo óptimo para implantar en los ordenamientos las distintas medidas antidiscriminatorias, así como para construir una visión más completa y cabal de la igualdad en el marco del constitucionalismo actual.

En primer lugar, cabe decir que la labor del Tribunal Constitucional español en la deconstrucción de las discriminaciones existentes por razón de sexo ha sido ciclópea, ya que inició su andadura partiendo de una realidad cimentada sobre una arraigada postergación de la mujer social y jurídica: la sociedad discriminaba, pero también lo hacía el derecho de manera grave. Discriminación que se producía en todos los ámbitos, en el político (el sufragio femenino no se reconoció hasta 1931); en el civil, hasta la aprobación de la Ley 14/1975, de 2 de mayo, de reforma de determinados artículos del Código Civil y del Código de Comercio, no se amplió la capacidad de obrar de la mujer, aunque tampoco se logró una plena equiparación entre los cónyuges; en el penal, que preveía graves diferencias de trato por razón de sexo, siempre en beneficio del varón. Sirva de ejemplo que, como recuerda López Pelegrín (2009: 226), los delitos sexuales eran concebidos como delitos contra la honestidad y el depositario de la honra de la esposa era precisamente su marido. Un ordenamiento y una sociedad en los que la violencia que sufría la mujer, por el hecho de ser mujer, se consideraba más bien una cuestión privada que convenía silenciar. Y la discriminación se evidenciaba, sobre todo, en el orden laboral.

Ante esta situación, el Tribunal Constitucional español se enfrentó a la dificultosa tarea de ajustar el ordenamiento a un texto constitucional (el de 1978) que, por primera vez en la historia constitucional española, proclamaba el reconocimiento de la mujer como sujeto de derechos, en iguales términos que el hombre; desempeñando una labor decisiva, ya que a través de sus pronunciamientos fue desterrando las normas preconstitucionales que contenían auténticas discriminaciones hacia la mujer. De tal forma que el ordenamiento español se fue desprendiendo de un buen número de disposiciones discriminatorias, suponiendo, así, un avance sustancial en la consecución de la igualdad entre hombre y mujer. Que esa igualdad, que ha ido calando en el ordenamiento, lo haya hecho también en la sociedad ya es mucho más cuestionable.

\section{LA CONFIGURACIÓN CONSTITUCIONAL DE LA IGUALDAD}

\section{LAS VERTIENTES DE LA IGUALDAD}

La construcción de la doctrina constitucional en esta lucha contra la discriminación por razón de sexo debía arrancar de un escenario constitucional 
en el que nuestro texto de 1978, al igual que los textos constitucionales más garantistas del constitucionalismo moderno, forja la igualdad como piedra angular de todo el edificio constitucional; confiriéndole un carácter triédrico, a partir del cual el Tribunal lo ha completado y enriquecido:

a. Por un lado, la igualdad se articula como un valor superior del ordenamiento, confiriéndole una eficacia trascendente y determinando que toda situación de desigualdad existente a la entrada en vigor de la Constitución sea incompatible con su orden de valores. La igualdad como valor superior del ordenamiento jurídico no solo tiene trascendencia dogmática, sino también metodológica, pues concede al criterio interpretativo igualitario un peso más fuerte que a criterios derivados de otros intereses o valores que no estén específicamente primados en el propio texto constitucional (López Guerra, 2000: 22).

b. En segundo lugar, se configura la igualdad de trato (igualdad formal o jurídica), esto es, el derecho a no ser tratado jurídicamente de manera diferente a quienes se encuentren en la misma situación; por lo que toda diferencia ha de ser razonable, proporcionada y no arbitraria. En suma, demanda la razonabilidad de las diferencias de trato ${ }^{1}$.

A su vez, y, particularmente, la igualdad reclama una prohibición de discriminación ${ }^{2}$ por causas concretas y expresamente rechazables, incompatibles con la dignidad humana, consideradas como categorías sospechosas de discriminación, ya que son las que mayor número de discriminaciones han provocado históricamente, ocupando un papel estelar de entre todas ellas el sexo.

c. En tercer lugar, esta interdicción de la discriminación ha de ponerse en necesaria conexión con la regulación constitucional de la igualdad sustancial o material, como mandato dirigido a los poderes públicos en orden a la remoción de todos aquellos obstáculos que impidan su cabal realización. De esta dimensión deriva la necesidad de adoptar medidas que traten de asegurar la igualdad efectiva de oportunidades y de trato.

En consecuencia, el mandato constitucional no se agota con la interdicción de las discriminaciones, sino que va más allá: faculta y exige, principalmente, a los poderes públicos para que promuevan las condiciones y remuevan los obstáculos para que la igualdad sea real y efectiva, mediante

1 Línea mantenida desde la STC 22/191, de 2 de julio, que ha seguido manteniendo y puede encontrarse en diversos pronunciamientos posteriores, la más reciente es la STC 91/2019, de 3 de julio.

2 Este mandato múltiple del art. 14 ya fue apuntado por Rodríguez Piñero y Fernández López (1986): 172 y 173 y, como puede observarse, el mismo Tribunal Constitucional se hace eco de esta doble dimensión en diversas Sentencias: 128/1987, de 18 de julio; 229/1992, de 14 de diciembre; 126/1997, de 3 de julio, entre otras. 
la adopción de medidas que tengan como objetivo nivelar las situaciones de desequilibrio con el fin de superar dichas desigualdades. El resultado es, pues, su configuración como un elemento nuclear de todo el orden constitucional, partiendo de un contenido proteico que vertebra dicho orden en aras de alcanzar una igualdad real, desterrando las desigualdades estructurales ${ }^{3}$.

\section{IGUALDAD VERSUS UNIFORMIDAD Y EL CANON DE CONSTITUCIONALIDAD DE LAS DIFERENCIAS DE TRATO}

La igualdad formal es un derecho subjetivo de los ciudadanos a obtener un trato igual, que obliga y limita a los poderes públicos a respetarlo y que exige que los supuestos de hecho iguales sean tratados idénticamente en sus consecuencias jurídicas, pero ello no impide introducir diferencias de trato. Ciertamente, la igualdad no es uniformidad y, en consecuencia, la Constitución no impide los tratos desiguales, pues el tratamiento diverso de situaciones distintas «puede incluso venir exigido, en un Estado social y democrático de derecho, para la efectividad de los valores que la Constitución consagra con el carácter de superiores del ordenamiento" (STC 34/1981, de 10 de noviembre).

Si la igualdad jurídica ha de entenderse en el sentido apuntado por el Tribunal Constitucional de modo que a situaciones de hecho iguales han de corresponder soluciones jurídicas iguales, y a situaciones de hecho desiguales soluciones jurídicas desiguales, debemos plantearnos cómo enjuiciar una diferencia de trato para determinar su licitud o no. Las pautas interpretativas del Tribunal en este orden son apreciables.

En primer lugar, cabe determinar si esa desigualdad resulta artificiosa o injustificada por no venir fundada en criterios objetivos y razonables, de acuerdo con criterios y juicios de valor generalmente aceptados y proporcionados (STC 200/2001, de 4 de octubre).

En segundo lugar, la vertiente sustancial de la igualdad exige, en muchas ocasiones, las diferencias de trato, traduciéndose en lo que el Tribunal Constitucional ha denominado $e l$ "derecho desigual igualatorio»; esto es, la desigual situación de partida requiere la adopción de medidas que tiendan a reequilibrar dichas situaciones con el objetivo de igualarlas de modo real y efectivo. De lo contrario se produciría la «discriminación por indiferenciación», es decir, la provocada por el hecho de tratar de modo igual situaciones disímiles ${ }^{4}$.

3 La igualdad es «una idea que sin duda subyace a toda la estructura constitucional y, a través de ella, a todo el ordenamiento", Rubio Llorente (1991: 9).

4 SSTC 128/1987, de 16 de julio; 19/1989, de 31 de enero; 229/1992, de 14 de diciembre. 
Nos encontramos, pues, con toda una construcción jurisprudencial para enjuiciar las diferencias de trato dirigidas a la remoción de las situaciones de desigualdad en aras de alcanzar la igualdad real, de forma que su licitud pasa por superar el denominado "test de la igualdad», que el Tribunal Constitucional ha concretado en los siguientes términos ${ }^{5}$ :

a) La infracción la produce solo aquella desigualdad que introduce una diferencia entre situaciones que pueden considerarse iguales y que carece de una justificación objetiva y razonable.

b) El principio de igualdad exige que a iguales supuestos de hecho se apliquen iguales consecuencias jurídicas, debiendo considerarse iguales dos supuestos de hecho cuando la utilización o introducción de elementos diferenciadores sea arbitraria o carezca de fundamento racional.

c) El principio de igualdad no prohíbe al legislador cualquier desigualdad de trato, sino solo aquellas desigualdades que resulten artificiosas o injustificadas por no venir fundadas en criterios objetivos suficientemente razonables de acuerdo con criterios o juicios de valor generalmente aceptados.

d) Por último, para que la diferenciación resulte constitucionalmente lícita es indispensable además que las consecuencias jurídicas que resultan de tal distinción sean adecuadas y proporcionadas a dicho fin, evitando resultados especialmente gravosos o desmedidos ${ }^{6}$.

\section{LA DISCRIMINACIÓN POR RAZÓN DE SEXO'}

Que esta cláusula sea la que ha dado lugar a un mayor número de pronunciamientos del Tribunal no sorprende a nadie si atendemos a la severa realidad de la discriminación por razón de sexo, tan evidente y con tantas plasmaciones normativas y fácticas. Adviértase que en el sexo confluyen, en muchas ocasiones, otras de las categorías sospechosas de discriminación; es, pues, un motivo que casi siempre está presente o que se adiciona a las demás causas.

El Tribunal, de forma amplia y cabal, entiende que la prohibición de discriminación por razón de sexo comprende no solo aquellos tratamientos peyorativos que encuentren su fundamento en la pura y simple constatación

5 SSTC 22/1981, de 2 de julio; 49/1982, de 14 de julio; 2/1983, de 24 de enero; 23/1984, de 20 de febrero; 209/1987, de 22 de diciembre; 209/1988, de 10 de noviembre; 20/1991, de 31 de enero; 110/1993, de 25 de marzo; 177/1993, de 31 de mayo; 340/1993, de 16 de noviembre; 117/1998, de 2 de junio; y 200/2001, de 4 de octubre.

6 STC 76/1990, de 26 de abril.

7 Aludimos al término sexo porque es el que utiliza el texto constitucional. 
del sexo de la persona perjudicada, sino que también engloba estos mismos tratamientos cuando se fundan en la concurrencia de condiciones o circunstancias que tengan con el sexo de la persona una relación de conexión directa e inequívoca (por ejemplo, el embarazo ${ }^{8}$ ). Así lo iremos viendo a lo largo de este trabajo.

\section{1. ¿̇ES NECESARIO JUSTIFICAR QUE EL SEXO ES UNA CATEGORÍA SOSPECHOSA DE LA DISCRIMINACIÓN QUE REQUIERE TRATAMIENTOS DESIGUALES PARA SU REPARACIÓN?}

Es incuestionable que las mujeres ni se han encontrado ni se encuentran en igual situación de partida que los hombres; las diferencias basadas en el sexo las han colocado en un escenario de postergación y de desventaja, por ello debemos plantearnos cómo cumplir con un mandato constitucional que demanda acabar con dichas situaciones de desigualdad, deviniendo ineludible reequilibrar lo que está en desequilibrio, lo que no es igual. Y ello solo es posible conseguirlo, por un lado, tratando desigualmente lo que es desigual; por otro, proporcionando medidas positivas de reequilibrio, ya que no se reequilibra con medidas neutras, pues, como ha advertido Fernando Rey (2004: 69), «la adopción de un Derecho neutro no es una decisión neutral».

Sin embargo, el Tribunal Constitucional no siempre asumió la necesidad de tratamientos diferenciados en atención al sexo con el objeto de reequilibrar la diferente situación de hecho. Es más, en su jurisprudencia pueden apreciarse diversas líneas evolutivas que van desde «una valoración formal de la igualdad hacia una tutela antidiscriminatoria» (Balaguer, 1991: 33) ${ }^{9}$. Su afirmación de que el sexo en sí mismo no puede ser motivo de trato desigual (Sentencia 207/1987, de 22 de diciembre) es claro exponente de esta posición.

Se trata de una primera línea doctrinal neutra en la que el Tribunal, en su pretensión de equiparar al hombre y a la mujer, no aceptó los tratamientos diferenciados cuyo sujeto beneficiario de protección fuera la mujer, pues ello, en tales términos, lo entendía contrario al art. $14 \mathrm{CE}$ (igualdad formal) ${ }^{10}$. En

8 Véase SSTC 166/1988, de 26 de septiembre; 173/1994, de 7 de junio; 136/1996, de 23 de julio; 20/2001, de 29 de enero; 41/2002.

9 En el mismo sentido, Rodríguez-Piñero (1992). Asimismo, afirma Elosegui (1998:, 12), que «en su afán de equiparación, el Tribunal defiende un modelo asimilacionista, que entiende la igualdad como homogenización absoluta entre varón y mujer; una igualdad que no tiene en cuenta apenas las diferencias; una igualdad poco realista y poco atenta a la necesidad de un período de adaptación y transición en la reestructuración social de los nuevos roles sociales y culturales asumidos por el varón y la mujer».

10 Claros exponentes de esta línea jurisprudencial son las Sentencias 81/1982, de 21 de diciembre; 103/1983, de 22 de noviembre, y 104/1983, de 24 de noviembre. 
consecuencia, en los conflictos planteados procuró, en todo momento, una equiparación entre hombres y mujeres ${ }^{11}$, olvidando las circunstancias históricas subyacentes de desequilibrio. Explica muy bien esta posición la Sentencia 103/1983, de 22 de noviembre, en la que el Tribunal amplió la pensión de viudedad también a los viudos, acogiéndose a una interpretación exclusivamente formal y muy alejada de la igualdad sustancial, ya que pretendía equiparar situaciones que realmente eran desiguales. En efecto, la razón por la que solo la mujer recibía dicha pensión respondía al hecho de que convertirse en viuda entrañaba la pérdida de su única fuente de financiación, que era la que le procuraba el varón; pues para ella contraer matrimonio implicaba, mayoritariamente, abandonar su trabajo para dedicarse a las labores del hogar; consecuencia que no se anudaba al varón que contraía. Era explicable, pues, que solo quien quedaba en situación de desamparo por el fallecimiento de un cónyuge fuera el beneficiario del subsidio; el hombre que perdía a su mujer seguía trabajando igual. Diferencias fácticas que exigían diferentes soluciones que el Tribunal no advirtió; pero sí el voto particular que formuló Rubio Llorente.

Más tarde, el Tribunal mantuvo una línea en la que, apartándose de la formal igualdad de trato, pasó a aceptar no solo la licitud, sino también la exigencia constitucional de las medidas dirigidas a conseguir la igualdad de oportunidades entre ambos sexos. Dicha posición supuso un abandono del criterio neutro seguido hasta el momento, ya que pasó a admitir los tratamientos favorables en favor de las mujeres para acabar con la histórica situación de desigualdad. Esta etapa se inició con la Sentencia 128/1987, de 16 de julio (Guarderías Infantiles ${ }^{12}$ ) calificada como leading-case, en la que, finalmente, reconoció que la exclusión de la discriminación por razón de sexo halla su razón concreta en la voluntad de terminar con la histórica situación de inferioridad en que, en la vida social y jurídica, se había colocado a la población femenina. Sentencia a la que nos referiremos con más detenimiento al abordar el derecho antidiscriminatorio.

Si bien el Tribunal Constitucional no olvida definitivamente la visión neutra inicial, manteniéndola en algunas sentencias ${ }^{13}$, ello va a ser más

11 STC 81/1982, de 21 de diciembre, en la que se recurría por parte de los varones la mayor retribución de las enfermeras en relación con las horas de trabajo extras que establecía el art. 50 del Estatuto del Personal Sanitario Auxiliar Titulado y Auxiliar de Clínica de la Seguridad Social de 26 de abril de 1973. El Tribunal entendió que la medida discriminaba a los varones, y, por tanto, la rechazó.

12 Se analiza en ella la demanda del actor contra las prestaciones en concepto de guarderías reconocidas a todas las mujeres trabajadoras del Instituto Nacional de Salud que, independientemente de su estado civil, tuvieran hijos menores de seis años, mientras que a los hombres se les exigía para recibir dicha ayuda la condición de viudo.

13 Véase Sentencia 253/1988, de 20 de diciembre, relativa a la pensión de viudedad para los viudos —SOVI_ y las demás relativas a esta materia: SSTC 144/1989, 18 de 
ocasional. La nueva línea del Tribunal implica una interpretación que toma como referencia el sexo como categoría sospechosa de la discriminación, permitiéndole sustentar diferencias de trato reequilibradoras, y conectando, así, igualdad jurídica, mandato antidiscriminatorio e igualdad sustancial.

\section{2. ¿̇QUÉ CONSECUENCIAS DERIVAN DE QUE EL SEXO SEA UNA CATEGORÍA SOSPECHOSA DE LA DISCRIMINACIÓN?}

La consideración del sexo como una categoría sospechosa de la discriminación le confiere una protección reforzada que aboca a la necesidad de usar en el juicio de legitimidad constitucional un canon mucho más estricto, así como un mayor rigor respecto a las exigencias materiales de proporcionalidad, y operando una inversión de la carga de la prueba ${ }^{14}$.

En efecto, que el sexo sea una de las categorías sospechosas de la discriminación tiene, también, su incidencia en el ámbito procesal, al posibilitar la inversión de la carga de la prueba. Así, el Tribunal Constitucional ha sostenido que cuando se prueba indiciariamente que un despido pueda enmascarar una lesión de los derechos fundamentales, incumbe al empresario acreditar que su decisión obedece a motivos razonables y ajenos a todo propósito atentatorio del derecho a no ser discriminado por razón de sexo. Esto implica, además, que se deriva una mayor exigencia para el juzgador, pues le obliga a que, ante una presunta discriminación por razón de sexo, no se limite a afirmar que no son suficientes las pruebas aportadas por el actor, sino que ha de expresar los motivos por los cuales entiende que no existe la aparente discriminación.

Dicha inversión de la carga de la prueba, no obstante, exige del demandante cierta diligencia probatoria; $y$, por tanto, el actor ha de probar en primer lugar, la existencia real y efectiva de una diferencia de trato en segundo lugar, la existencia de indicios racionales de los que se pueda deducir que esa desigualdad está vinculada al sexo ${ }^{15}$. Ahora bien, lo que no se impone al empresario es la "prueba diabólica» de un hecho negativo - la no discriminación-, sino la de la razonabilidad y proporcionalidad de la medida adoptada y su carácter enteramente ajeno a todo propósito atentatorio de derechos fundamentales ${ }^{16}$. Exigiéndose del actor aportar una "prueba verosímil» o "principio de prueba» revelador de la existencia de un panorama discriminatorio general o de hechos

diciembre; 176/1989, de 30 de octubre; 142/1990, de 20 de septiembre; 158/1990, de 18 de octubre; 58/1991, de 14 de marzo.

14 SSTC 126/1997, de 3 de julio, FJ 8, 229/1992, de 14 de diciembre, FJ 4; 75/1983, de 3 de agosto, FFJJ 6 y 7; 209/1988, de 10 de noviembre, 81/1982, de 21 de diciembre, FJ 2). Ya aplicado desde antaño en Norteamérica como strict scrutiny.

15 STC 90/1997, de 6 de mayo.

16 SSTC 136/1996, de 23 de julio; 41/2002, de 25 de febrero. 
de los que surja la sospecha vehemente de una discriminación por razón de sexo.

Asimismo, la afectación del derecho a la no discriminación por razón de sexo (art. $14 \mathrm{CE}$ ) aboca a unas exigencias del canon de razonabilidad y motivación reforzadas del derecho fundamental a la tutela judicial efectiva (art. 24.1 CE) (por todas, 111/2018, de 17 de octubre).

\section{ALCANCE DEL MANDATO ANTIDISCRIMINATORIO}

La igualdad y la interdicción de la discriminación por razón de sexo se proclaman frente a los poderes públicos; no solo es un límite formal, sino también material, que afecta al contenido de la ley; del mismo modo que en la aplicación de la ley vincula al ejecutivo y al judicial.

Ni Gobierno ni Administración pueden, en el ejercicio de sus funciones, conceder un trato distinto a quienes se encuentren en la misma situación, sujetándose las actuaciones arbitrarias al control de la jurisdicción contencioso-administrativa y, en último término, del Tribunal Constitucional mediante la interposición de un recurso de amparo constitucional.

En relación con el Poder Judicial, el principio de interdicción de la arbitrariedad de los poderes públicos cuando se trata de la aplicación de la ley por un mismo órgano judicial, obliga a que las soluciones ofrecidas a los casos individualizados obedezcan a un criterio general de interpretación y aplicación de la legalidad. Pero esta exigencia de igualdad ha de ser compatible con la independencia judicial, de modo que la diferente interpretación de las normas no puede considerarse en sí misma lesiva del derecho a la igualdad, sino que ha de cohonestarse con la posibilidad de que los jueces puedan cambiar su criterio; pues no existe un mandato de igualdad absoluta que obligue en todo caso al tratamiento igual de los supuestos iguales. Dichos cambios podrán operarse siguiendo unas exigencias: no se conculca la igualdad cuando las decisiones que otorgan un trato diferente provengan de órganos distintos (STC 168/1989, de 16 de octubre); aunque cabe que un mismo órgano modifique sus decisiones de forma motivada, pues lo que se prohíbe son las diferencias de tratamiento arbitrarias por no justificadas (STC 63/1984, de 21 de mayo). Además, ha de tenerse en cuenta que «cada órgano solo puede ser comparado consigo mismo» (Rubio Llorente, 1995: 122); de forma que, como expresa el Tribunal Constitucional, «uno de los requisitos para realizar la comparación que toda discriminación en la aplicación de la ley lleva implícita es la identidad del órgano" (168/1989, de 16 de octubre).

En síntesis, en la medida en que el texto constitucional vincula positiva y negativamente a los poderes públicos, no cabe duda de que el respeto a la igualdad se impone a los órganos del poder público; de modo que la prohibición de discriminación opera en forma más intensa cuando se trata de un empleador de carácter público (SSTC 166/1988, de 26 de septiembre, y 114/2002, de 
20 de mayo). Pero ello no es suficiente. Hoy los derechos vinculan también a los ciudadanos; quedando superada la concepción inicial de los orígenes del constitucionalismo en la que los derechos eran límites a la actuación de los poderes públicos, de modo que primaba la autonomía de la voluntad frente a la injerencia de los poderes públicos. Ciertamente, los poderes públicos tienen un deber general positivo de realizar sus funciones de acuerdo con la Constitución para garantizar los derechos fundamentales. Pero los particulares tienen un deber general negativo de abstenerse de cualquier actuación que vulnere los derechos. Repárese que el ámbito laboral ha sido, por excelencia, campo abonado de discriminación, de forma que, desde un principio, el Tribunal remarcó que las relaciones entre particulares, aunque matizadas por el principio de la autonomía de la voluntad «no quedan, excluidas del ámbito de aplicación del principio de igualdad, y la autonomía de las partes ha de respetar tanto el principio constitucional de no discriminación como aquellas reglas, de rango constitucional u ordinario, de las que se derive la necesidad de igualdad de trato ${ }^{17}$.

Se trata, así, de una autonomía de la voluntad que está limitada solo por la prohibición de incurrir en discriminaciones contrarias al orden público constitucional (108/1989, de 8 de junio). En esta dirección, como veremos más adelante, la doctrina del Tribunal ha ido reforzando la vinculación de los terceros a dicha igualdad y prohibición de discriminación por razón de sexo en diferentes ámbitos ${ }^{18}$, muy particularmente en el orden laboral.

\section{LA INTERDICCIÓN DE DISCRIMINACIÓN}

El Tribunal Constitucional, en sus sentencias, ha ido asumiendo y perfeccionando diversas categorías conceptuales que tienen como objeto asegurar la igualdad, y que han tenido su reflejo en el ordenamiento, ya que muchas de ellas se han incorporado a la legislación tras su reconocimiento jurisprudencial.

\section{DISCRIMINACIÓN DIRECTA}

Se produce cuando una persona es tratada de modo menos favorable que otra en una situación análoga a causa de su género, sin que existe justificación objetiva y razonable. Pero como ha recordado en diversas ocasiones este Tribunal, este tipo de discriminación también engloba estos mismos tratamientos cuando

17 STC 177/1988, de 10 de octubre.

18 Por ello, el juicio aplicado a una diferenciación de un empresario es igual de estricto que el que se aplica a una diferenciación perjudicial para la mujer realizada por los poderes públicos. Giménez Gluk (2004). 
se funden en la concurrencia de condiciones o circunstancias que tengan con el sexo de la persona una relación de conexión directa e inequívoca ${ }^{19}$.

Dentro de lo que constituyen discriminaciones directas podemos encontrarnos con numerosos pronunciamientos que han ido desterrando la discriminación en diversos ámbitos:

\subsection{Las cláusulas de celibato}

Ha correspondido al Tribunal eliminar del ordenamiento español diversas normas que suponían una clara discriminación directa: es el caso de las denominadas cláusulas de celibato, sobre las que el Tribunal ha venido afirmando, en numerosas ocasiones, que la suspensión del contrato de trabajo "para el personal femenino", por el hecho de contraer matrimonio, constituye una discriminación por razón del sexo, pues no se hace derivar idéntica consecuencia en relación con el personal masculino de la misma empresa que contrajera matrimonio ${ }^{20}$.

En el mismo sentido, ha considerado que permitir la reanudación del nexo contractual únicamente en los supuestos de incapacidad o fallecimiento del marido, si bien era coherente con el contexto social y normativo de la época, que atribuía originariamente al consorte de sexo masculino la condición de cabeza de familia, pugna claramente con la igualdad jurídica de los cónyuges en el matrimonio y en las responsabilidades familiares (59/1993, de 15 de febrero).

\subsection{Diferencias salariales basadas en el sexo}

La brecha salarial, hoy en día, sigue siendo real2 ${ }^{21}$; el salario recibido por la mujer es inferior al que recibe el varón, y no solo ello, sino que entre aquellas

19 Tal sucede con el embarazo, elemento o factor diferencial que, en tanto que hecho biológico incontrovertible, incide de forma exclusiva sobre las mujeres (SSTC 173/1994, de 7 de junio; 20/2001, de 29 de enero; 41/2002, de 25 de febrero; 17/2003, de 30 de enero; 98/2003, de 2 de junio; 175/2005, de 4 de julio; 214/2006, de 3 de julio; y 342/2006, de 11 de diciembre).

20 En la Sentencia 7/1983, de 14 de febrero declara que el art. 107.c de la Reglamentación de Trabajo de 1958 de la Compañía Telefónica Nacional de España es discriminatoria por razón de sexo, deviniendo incompatible con la Constitución española de 1978, y, por tanto, derogada por oposición al artículo 14. Dicha Reglamentación establecía la excedencia forzosa por razón de matrimonio para el personal femenino, con reconocimiento de la posibilidad de solicitar el reingreso cuando cada una de las mujeres se constituyera en cabeza de familia.

21 Datos del Instituto Nacional de Estadística; en cuya página puede encontrarse un estudio detallado sobre este tema. 
personas que reciben un salario inferior al mínimo, la mayoría son mujeres. Y ello pese a que la discriminación salarial por razón de sexo está expresamente vetada en la Constitución como una de las concreciones de la cláusula general de igualdad; no obstante, el salario ha constituido siempre uno de los mayores focos discriminatorios, lo que ha generado numerosos pronunciamientos del Tribunal Constitucional ${ }^{22}$.

Cabe destacar la interpretación que el Alto Órgano inicia en la Sentencia 145/1991, de 1 de julio, en la que estima que solo cabe calibrar la legalidad de la diferencia de trato en materia salarial en atención a la diferencia de los trabajos efectivamente prestados. Por tanto, igual trabajo es igual salario, independientemente del sexo. Ahora bien, ello no es suficiente, ya que tampoco puede utilizarse el sexo como justificación para establecer las distintas categorías profesionales.

Además, el principio constitucional de no discriminación en materia salarial incluye también la desigual valoración de trabajos no estrictamente iguales, pero equivalentes o de igual valor desde el punto de vista de la naturaleza y condiciones de prestación, cuando el elemento determinante para dicha valoración distinta sea el sexo (Lousada Arochena, 2015). Esta es la posición mantenida por el Tribunal de Justicia de la Unión Europea, reafirmando que, a igual trabajo, incluso un trabajo de igual valor, debe ser retribuido de la misma manera, a menos que la diferencia de retribución se justifique por razones objetivas ${ }^{23}$. En este sentido, advierte que no es solo la categoría profesional lo que determina que se realiza el mismo trabajo o trabajo de igual valor, sino que habrá que tomar en consideración un conjunto de factores como, por ejemplo, la naturaleza del trabajo, las condiciones de formación y las condiciones laborales.

No obstante, como ha advertido Fernando Rey (2000: 435), la jurisprudencia del TC en relación con la utilización del sexo como factor de clasificación de tareas dentro de las empresas, con la consiguiente desigualdad retributiva, es una jurisprudencia vacilante. Aunque, finalmente, el avance de la doctrina constitucional, en orden a la interdicción de las discriminaciones salariales, es loable, al extender la discriminación también a una indemnización por extinción de los contratos de trabajo que se calcula sobre la base de un salario discriminatorio, porque perpetúa la discriminación salarial sufrida por las trabajadoras (STC 183/2000, de 10 de julio).

22 Este tema ha sido uno de los que mayor reconocimiento ha tenido en el marco de la Unión Europea, tanto en diversas directivas como en importantes pronunciamientos del Tribunal de Justicia. Su estudio más detallado puede encontrarse en Navarro Nieto (2015).

23 STJUE en el asunto Brunnhofer, de 26 de junio de 2001, asunto C-381/99. 
La inversión de la carga de la prueba, a la que nos hemos referido con anterioridad, opera de lleno en esta materia. Así lo manifestó desde bien temprano el Tribunal de Justicia de las Comunidades Europeas cuando en la sentencia Danfoss, de 17 de octubre de 1989, al expresar que cuando una empresa aplica «un sistema retributivo caracterizado por la falta total de transparencia, recae sobre el empresario la carga de la prueba de que su política salarial no es discriminatoria, una vez que el trabajador femenino haya demostrado, con respecto a un grupo relativamente importante de trabajadores por cuenta ajena, que la retribución media de los trabajadores femeninos es inferior a la de trabajadores masculinos».

En muchas ocasiones, la discriminación salarial por razón de género está encubierta bajo una categoría que es la denominada discriminación indirecta. En este sentido, resulta de especial interés la reciente STC 91/2019, de 3 de julio, en la que anula el cálculo de la pensión en el trabajo a tiempo parcial por considerarlo discriminatorio para las mujeres. Es verdad que el TC ya se había pronunciado con anterioridad en relación con la exclusión y desprotección de los trabajadores a tiempo parcial; de hecho, el recurso fue planteado por un hombre que consideraba discriminatorio dicho calculo en el trabajo a tiempo parcial respecto de los contratos a tiempo completo. Pero la relevancia de esta sentencia deriva de que resuelve una autocuestión de inconstitucionalidad que la Sala Segunda decide elevar al Pleno del Tribunal, en clave de género; esto es, lo que se plantea es enjuiciar la compatibilidad con el principio constitucional de igualdad y con la prohibición de discriminación por razón de sexo de que la cuantía de la pensión de la seguridad social a la que tienen derecho esos trabajadores se reduzca en proporción a la parcialidad de la jornada, y de acuerdo con las reglas correctoras que contempla la disposición legal cuestionada.

El hecho de que el trabajo a tiempo parcial afecta muy mayoritariamente a las mujeres (76\%) conduce al Tribunal a «examinar con mayor cautela» el impacto de la regla de cálculo para descartar la existencia de esa discriminación indirecta por razón de sexo. Declarando, finalmente, que, no habiéndose demostrado que exista «una justificación objetiva y razonable» para la diferenciación entre las pensiones a tiempo completo y a tiempo parcial, se perjudica a estas últimas frente a las primeras, afectando mayoritariamente a las mujeres.

De hecho, el Tribunal Constitucional se hace eco de la sentencia del Tribunal de Justicia de la Unión Europea de 8 de mayo de 2019 (Villar Láiz ${ }^{24}$, en la que declaró que la normativa española en materia de cálculo de la pensión de jubilación de los trabajadores a tiempo parcial es contraria al derecho de la Unión Europea si se revela especialmente desventajosa para las trabajadoras.

24 STJUE en el asunto Violeta Villar Láiz, de 8 de mayo de 2019, asunto C-161/18. 


\subsection{Los tratos desfavorables basados en el embarazo o en la maternidad, por afectar solo a la mujer, constituyen discriminación por razón de sexo}

Partiendo de que el embarazo es un elemento o factor diferencial que, por razones obvias, incide de forma exclusiva sobre las mujeres, el Tribunal ha venido consolidando una línea jurisprudencial ${ }^{25}$ en la que reafirma que la discriminación por razón de sexo comprende también tratamientos basados en el embarazo, elemento que, por razones obvias, incide de forma exclusiva sobre las mujeres ${ }^{26}$. A partir de ahí, en diversas ocasiones, ha reafirmado que las decisiones extintivas de las relaciones laborales basadas en el embarazo, al afectar exclusivamente a la mujer, constituyen una discriminación por razón de sexo.

Estamos ante un supuesto que genera las denominadas «discriminaciones ocultas», ya que en diversas ocasiones suele suceder que el despido de la mujer se suele disfrazar en argumentos de rendimiento, cuando, en realidad, se debe a un embarazo.

La maternidad, el embarazo y el parto son realidades biológicas diferenciadas de obligatoria protección, derivada directamente del art. 39.2 CE, que se refiere a la protección integral de las madres. Por tanto, las ventajas que se determinen para la mujer no pueden considerarse discriminatorias para el hombre (SSTC 109/1993 y 75/2011). Por ello, los órganos administrativos tienen la obligación de adoptar medidas flexibles que impidan que la maternidad sea un obstáculo para el acceso al empleo público y, al ser la maternidad un factor protegido, cualquier perjuicio laboral que sufra la mujer trabajadora por el solo hecho de ser madre supone un menoscabo del contenido esencial del derecho a no ser discriminada (STC 198/2019).

Son distintos los supuestos que pueden afectar a la mujer por este motivo:

(a) Despido por embarazo

Cuando se afirme que la causa del despido es el embarazo habrá de consignarse la existencia de tal embarazo y el conocimiento o desconocimiento del mismo por parte de la empresa demandada; en consecuencia, si consta expresamente que la empresa no conocía el embarazo cuando procedió al despido, no se podrá imputar la vulneración a la decisión extintiva empresarial, ya que

25 SSTC 94/1984, de 16 de octubre; 166/ 1988, de 26 de septiembre; 173/1994, de 7 de junio; 136/1996, de 23 de julio.

26 El Tribunal Constitucional, al fijar esta línea interpretativa, se basa en el Ordenamiento comunitario: Directiva 76/207/CEE, de la que se desprende que el despido de una trabajadora por razón de su embarazo constituye una discriminación directa basada en el sexo (Sentencia del TJCE de 8 de noviembre de 1990, asunto "Hertz»), como también lo es la negativa a contratar a una mujer embarazada (Sentencia de la misma fecha recaída en el asunto "Dekker». 
la empresa no ha basado el despido en el conocimiento del embarazo (STC 41/2002).

Así pues, para determinar si las resoluciones judiciales impugnadas vulneran la interdicción de discriminación por razón de sexo el Tribunal ha de analizar, «a la vista de las circunstancias del caso concreto, si la trabajadora recurrente en amparo aportó indicios de discriminación suficientes y si, en tal supuesto, como consecuencia de la inversión de la carga de la prueba, la empleadora cumplió con su obligación de rebatirlos justificando que su actuación fue absolutamente ajena a todo propósito atentatorio de derechos fundamentales» (STC 17/2007).

Pero distingue entre el despido que tiene su origen en el embarazo, con conocimiento del empleador y el despido en los casos en los que el empresario no conociera el estado de gestación, dando lugar a la improcedencia del despido y no su nulidad. (SSTC 92/2008 y 124/2009).

Diferente es la extinción del contrato de trabajo en periodo de prueba, sin que tenga su justificación en el embarazo, que será nula si se produce con vulneración de derechos fundamentales, como sucederá si la decisión empresarial es una reacción al embarazo de la trabajadora (STC 17/2007, de 12 de febrero). Sin embargo, dada la distinta naturaleza jurídica de las instituciones del despido y de la extinción del contrato en el periodo de prueba, el desistimiento empresarial durante dicho periodo de prueba, cuando la empresa no conoce el estado de gestación de la trabajadora, no resulta discriminatorio si no se acredita móvil discriminatorio en la decisión extintiva (173/2013, de 10 de octubre).

(b) Impedir el acceso de la recurrente a la plaza obtenida en proceso selectivo por encontrarse en estado de maternidad supone una discriminación directa por razón de sexo (STC 108/2019, de 30 de septiembre).

(c) La diferente duración de los permisos de maternidad no es discriminatoria.

La atribución del permiso por maternidad, con la correlativa prestación de la seguridad social a la mujer trabajadora con una duración superior a la que se reconoce al padre, no es discriminatoria para el varón. Siendo diferentes las situaciones que se traen a comparación, no puede reputarse como lesiva del derecho a la igualdad ante la ley (art. $14 \mathrm{CE})^{27}$.

No obstante, el voto particular de Balaguer Callejón advierte que la sentencia ignora que existe un efecto claro de discriminación indirecta de las mujeres, por lo que un Tribunal Constitucional de este siglo debería haber reconocido la necesaria evolución de la realidad social, y profundizado en el análisis de los efectos reales de las medidas de protección que aquí se cuestionan.

27 SSTC 111/2018, de 17 de octubre; 108/2019, de 30 de septiembre; 138/2018, de 17 de diciembre; $2 / 2019$, de 14 de enero. 


\subsection{Acoso sexual}

Con meridiana claridad, el Tribunal Constitucional ha reconocido que el acoso sexual y el acoso por razón de sexo en el trabajo tienen la consideración de discriminación directa por razón de sexo (STC 159/2016, de 22 de septiembre); fijando en la objetividad y la gravedad del comportamiento los presupuestos sobre los que asienta la doctrina constitucional la posible existencia de acoso sexual (136/2001, de 18 de junio). Es cierto que reconoce que el derecho a la protección del trabajador contra el conocido también como «acoso sexual» se inscribe en el derecho a la intimidad personal. Pero, asimismo, considera que el acoso sexual en el ámbito profesional puede también tener un engarce constitucional con la interdicción de la discriminación en el trabajo por razón de sexo (art. 14 CE); en la medida en que está presente siempre en el trasfondo, afectando notoriamente con mayor frecuencia y más intensidad a la mujer que al hombre, como consecuencia de condiciones históricas de inferioridad o debilidad de ellas en el mercado de trabajo y en el lugar de su prestación (STC 224/1999, de 13 de diciembre).

\subsection{La violencia de género: una atroz discriminación directa}

La violencia en el marco del género se basa y explica en razones de discriminación, al ser expresión de la desigualdad que ha desembocado en la concepción de dominación por parte del varón y la consustancial postergación de la mujer. Posición radicalmente contraria al orden constitucional.

La virulencia de sus manifestaciones propició la aprobación de la Ley Orgánica de Medidas de Protección Integral contra la Violencia de Género (Ley $1 / 2004$, de 29 de diciembre, en adelante LOVG), que descansa sobre el reconocimiento de la relación causal entre género y violencia. La LOVG regula de forma integral este fenómeno violento, conteniendo un amplio abanico de medidas de distinto orden: tutela institucional de la lucha contra la violencia de género mediante la creación de determinados órganos, medidas en el ámbito sanitario, la prohibición de publicidad sexista, medidas en el ámbito educativo, etc., que no pueden considerarse medidas propias del derecho antidiscriminatorio, circunstancia que explicaría la ausencia de conflictividad constitucional de las mismas.

Asimismo, contiene medidas de acción positiva, que se enmarcan en los ámbitos laboral, económico y prestacional. Todas ellas tienen pleno encaje constitucional, al proyectarse en los ámbitos propios de las acciones positivas.

En tercer término, recoge un conjunto de medidas relativas al ámbito penal, que son las que mayor polémica han generado, ya que prevé delitos específicos o formas agravadas de los mismos en los que el autor es el hombre y los sujetos pasivos son la mujer y las personas especialmente vulnerables. 
Estas diferencias punitivas han constituido el epicentro sobre el que se han planteado las mayores dudas de constitucionalidad al considerar que a través de ellas se excluye al hombre de la tutela penal reforzada (que se confiere solo a la mujer) y se le sanciona más duramente; por tanto, son medidas que endurecen la respuesta punitiva en atención a la diferenciación sexual de los sujetos del delito. Estas previsiones entrarían en contradicción con la doctrina sentada por el Tribunal Constitucional en diversas sentencias, en la que se afirma que la Constitución española «consagra sin duda el principio de culpabilidad como principio estructural básico del Derecho penal, de manera que no sería constitucionalmente legítimo un derecho penal «de autor» que determinara las penas en atención a la personalidad del reo y no según la culpabilidad de este en la comisión de los hechos (SSTC 65/1986, 14/1988, STC 150/1991 y 246/1991).

Su cuestionamiento se materializó por parte de los órganos jurisdiccionales mediante el planteamiento de numerosas cuestiones de inconstitucionalidad ante el TC, fundadas en el difícil encaje constitucional de estas medidas.

Para analizar la respuesta del Tribunal Constitucional deberíamos diferenciar entre la constitucionalidad o no de la propia norma, las diversas medidas que establece $y$, por último, referirnos a las penales.

(a) La Ley, en su conjunto, y como respuesta integral al problema que pretende resolver, procede a regular de modo desigual situaciones que son diferentes objetivamente. Combate una situación real que descansa sobre unas cifras alarmantes que revelan la diferente posición en la que se encuentran los destinatarios de la norma en las situaciones de violencia. Estamos, pues, ante situaciones de hecho desiguales que exigen constitucionalmente un tratamiento diferenciado. El interés prevalente para su adopción es la salvaguarda de la integridad física y moral, de la vida y de la salud de la mujer; fines constitucionales lo suficientemente trascendentes para exigir las diferencias de trato objetivas y razonables que establece la norma (Sentencia 59/2008, de 15 de mayo).

(b) La palmaria legitimidad constitucional de la finalidad de la LOVG.

En la misma sentencia, y en las posteriores que irá dictando, el Tribunal afirma dicha legitimidad fundándola en las siguientes argumentos: a) la Ley «tiene como finalidad principal prevenir las agresiones que en el ámbito de la pareja se producen como manifestación del dominio del hombre sobre la mujer en tal contexto; su pretensión así es la de proteger a la mujer en un ámbito en el que el legislador aprecia que sus bienes básicos (vida, integridad física y salud) y su libertad y dignidad mismas están insuficientemente protegidos»; b) el objetivo es combatir el «origen de un abominable tipo de violencia que se genera en un contexto de desigualdad y de hacerlo con distintas clases de medidas, entre ellas las penales» (por todas, STC 59/2008, de 14 de mayo; STC 52/2010, de 4 de octubre; STC 41/2010, de 22 de julio).

A mi juicio, la interpretación realizada por el Tribunal Constitucional es loable, ya que acierta al reconocer que mediante la lacra de la violencia de 
género no se atacan los bienes básicos de la mujer, sino también la libertad y dignidad de la víctima, precisamente porque en el sustrato de esta manifestación de violencia se encuentra la consideración de la mujer como instrumento de reafirmación machista, y su negación como persona.

Creo que el soporte legitimador de la LOGV se acomoda plenamente a las exigencias del art. $14 \mathrm{CE}$ (que regula la igualdad formal y la prohibición de discriminación), ya que la gravedad de la violencia de género es de tal magnitud que alcanza el grado de alarma social, requiriendo la intervención responsable de los poderes públicos.

(c) El cuestionamiento de las diferencias de trato penales.

Pero, la discusión deriva de dar una respuesta penal desigual a conductas que son objetivamente idénticas, salvo por un único elemento de diferenciación: el sexo del sujeto activo o pasivo del delito.

Las STC 59/2008, de 14 de mayo, y STC 45/2009, de 19 de febrero, son las que constituyen los principales pronunciamientos en los que se contiene la doctrina constitucional y a los que se remitirá el TC en la resolución de la mayoría de las demás cuestiones planteadas. En ellas, el Tribunal, al igual que se hace en los autos de planteamiento, sitúa el punto de partida para el enjuiciamiento de las diferencias de trato penales en el juicio de razonabilidad de dichas diferencias, sin considerarlas acciones positivas. Planteamiento que compartimos por coincidir con el que mantuvimos en nuestro trabajo inicial en el que sosteníamos que las medidas penales previstas en la ley no pueden calificarse ni como discriminación positiva ni como acciones positivas; por tanto, manteníamos que su cabal enjuiciamiento debía hacerse desde criterio de la diferenciación objetiva, razonable y proporcional (Ridaura, 2018). Si bien compartimos el enfoque del enjuiciamiento que realiza el Tribunal Constitucional, sin embargo, disentimos en cuanto a la decisión final que adopta.

El Tribunal Constitucional toma como punto de partida la exclusividad del legislador para el diseño de la política criminal que le confiere una amplia libertad, y entiende que la diferenciación normativa la sustenta el legislador en su «voluntad de sancionar más unas agresiones que entiende que son más graves y más reprochables socialmente a partir del contexto relacional en el que se producen y a partir también de que tales conductas no son otra cosa... que el trasunto de una desigualdad en el ámbito de las relaciones de pareja de gravísimas consecuencias para quien de un modo constitucionalmente intolerable ostenta una posición subordinada ${ }^{28}$.

El TC entiende que la finalidad de la diferenciación introducida por el legislador en materia penal es la protección de la libertad y de la seguridad de las mujeres, «que el legislador entiende como insuficientemente protegid[a]s

28 SSTC 59/2008, de 14 de mayo; 41/2010, de 22 de julio; en idéntico sentido, SSTC 45/2009, de 19 de febrero; y 127/2009, de 26 de mayo. 
en el ámbito de las relaciones de pareja», y «la lucha contra la desigualdad de la mujer en dicho ámbito" (STC 59/2008, FJ 8).

La argumentación del Tribunal para salvar la constitucionalidad de las medidas cuestionadas, desde mi punto de vista, no consigue desterrar el factor del sexo de los sujetos activo y pasivo para justificar el diferente tratamiento penal, ya que es imposible hacerlo, pues el trasunto de la violencia machista es la desigualdad.

En otro orden de consideraciones, conviene resaltar, como también se ha puesto de manifiesto por diversos sectores doctrinales ${ }^{29}$, que la aplicación de la presunción de un móvil discriminatorio en toda conducta del varón constituye una presunción iuri et de iure; resultado que vulneraría la presunción de inocencia, así como la proporcionalidad en la sanción de conductas que no se ha habido posibilidad de probar. Por tanto, la presunción del móvil discriminatorio ha de ser en todo caso iuris tantum.

En síntesis, analizados los pronunciamientos del Tribunal, consideramos que:

1. La ley, que tiene como finalidad la erradicación de la violencia de género, abordando el problema de un modo integral, aparece como una exigencia constitucional.

La ley regula una situación particular — la de la violencia de género- que no tiene parangón con la violencia sufrida por el hombre por razón de su sexo. Estamos, pues, ante situaciones de hecho desiguales que exigen constitucionalmente un tratamiento diferenciado. La ley, además, encaja claramente con los instrumentos internacionales en los que se reclama una respuesta global a la violencia ejercida sobre las mujeres; textos que cumplen una función hermenéutica, de acuerdo con el art. 10.2 de nuestra Constitución.

2. Desde nuestro punto de vista, las medidas de distinto orden — señaladamente las acciones positivas - previstas en la ley tienen pleno encaje constitucional.

3. Sin embargo, las medidas penales no son ni acciones positivas, ni medidas de discriminación positiva; su conceptualización no se corresponde con ellas. Por ello, consideramos que su enjuiciamiento debe orientarse hacia la diferenciación objetiva y razonable.

Y, desde este punto de vista, dichas medidas penales no nos merecen un juicio positivo: no cumplen estrictamente ni con el test de la igualdad, ni con la adecuada concepción del derecho penal.

Sin embargo, no creemos que las sentencias analizadas del Tribunal interioricen cabalmente estos argumentos.

29 González Cussac (2009), Queralt Jiménez (2006), Larrauri Pijoan (2009) y Polaino-Orts (2008). 


\section{DISCRIMINACIÓN INDIRECTA}

Se trata de una categoría elaborada por el Tribunal norteamericano, y que paulatinamente se extenderá a otros ordenamientos. Es cierto que el primer pronunciamiento del Tribunal Supremo Federal de los Estados Unidos en la sentencia Griggs v. Duke Power Company, de 8 de marzo de 1971, está referido a discriminación racial. Pero, unos años más tarde, en 1977, la sentencia Dothards vs. Rawlinson, abordó la discriminación por razón de sexo, al establecerse unos requisitos para la selección de trabajadores que podían cumplir mayoritariamente los hombres, pero solo muy pocas mujeres (Serra, 2004).

Estamos ante un concepto de creación jurisprudencial, que se ha ido asumiendo por los ordenamientos, hasta generalizarse. De hecho, el Tribunal de Justicia de la Unión Europea lo recoge pronto en su Sentencia de 8 de abril de 1976, asunto Defrenne $I{ }^{30}$, refiriéndose a las discriminaciones indirectas y encubiertas. La discriminación indirecta no tardó en llegar al ordenamiento español fue en la Sentencia 145/1991, de 1 julio (caso Gregorio Marañón), en la que el Tribunal concluye que la prohibición constitucional de discriminación incluye no solo la noción de discriminación directa (tratamiento diferenciado perjudicial en razón del sexo donde este sea objeto de consideración directa), sino también la noción de discriminación indirecta. Por tal entiende el tratamiento formalmente neutro o no discriminatorio, del que se deriva, por las diversas condiciones fácticas que se dan entre los trabajadores de uno y otro sexo, un impacto adverso sobre los miembros de un determinado sexo; salvo que este tratamiento responda a una finalidad legítima y utilice medios proporcionados, adecuados y necesarios para conseguirla ${ }^{31}$. El concepto de discriminación indirecta es, hoy en día, una categoría que está bien arraigada en la doctrina constitucional.

\section{DISCRIMINACIÓN POR ASOCIACIÓN}

Se trata de una categoría referida a las discriminaciones que pueden sufrir algunas personas por su relación con otras de especiales características.

30 Defrenne II (43/75, sentencia de 8 de abril de 1976), seguido de los casos Macarthys Ltd. vs. Wendy Smith en 1980; STJCE de 31 de marzo de 1981, el caso Jenkins vs. Kingsgate (Clothing Productions) Ltd.; Bilka-Kaufhaus GmbH vs. Weber Von Hartz, recogido en la STJCE de 13 de mayo de 1986. Categoría que se incorporó paulatinamente a las sucesivas directivas.

31 Doctrina que se reiterará en las SSTC 58/1994, de 28 de febrero; 286/1994, de 28 de noviembre; 147/1995, de 16 de octubre; 250/2000, de 30 de octubre; 253/2004, de 22 de diciembre. 
Generalmente, la mayoría de los casos se asocia con el sexo, de ahí que hagamos referencia al mismo, ya que constituye una de las razones que sin tomar como elemento principal el sexo, finalmente acaban repercutiendo, mayoritariamente, en las mujeres. Es un concepto acuñado por el Tribunal de Justicia de la Unión Europea el 17 de julio de 2008, en el caso Coleman en el que ha considerado que la discriminación por discapacidad protege también a aquellas personas que, sin estar ellas mismas discapacitadas, sufran discriminación directa o acoso en el empleo por estar vinculadas a una persona discapacitada. En ese supuesto, el Tribunal de Luxemburgo estimó que había habido discriminación laboral en el caso de un despido de una madre que cuidaba a su hijo discapacitado (Rey, 2017). El fundamento de esta decisión lo encuentra el Tribunal en la directiva que protege frente a la discriminación de las personas asociadas a una persona con discapacidad ${ }^{32}$.

Es cierto que el Tribunal Constitucional español, a día de hoy, no cuenta aún con sentencias relativas a esta categoría; pero sí que ha sido reconocida en sentencias de tribunales superiores (Cataluña, Andalucía) ${ }^{33}$. Se trata, pues, de una categoría en expansión que está siendo reconocida también en diversos ordenamientos, así como por el Tribunal Europeo de Derechos Humanos ${ }^{34}$.

\section{LA MULTIDISCRIMINACIÓN}

Se trata de supuestos en los que concurren dos o más rasgos sospechosos configurando una discriminación específica. Y es que, como indica Rosario Serra, la discriminación múltiple "parece tener nombre de mujer», ya que se encuentra en una situación de especial vulnerabilidad, pues en muchas ocasiones se produce una concurrencia de diversas causas de discriminación, que intensifican su riesgo de exclusión (Serra, 2015: 15).

Sin embargo, el Tribunal Constitucional español tampoco ha recibido aún esta causa pluricausal de discriminación. Por el contrario, España sí que ha sido condenada por el Tribunal Europeo de Derechos Humanos en un asunto

32 Directiva inspirada en la Americans with Disabilities Act de 1990 de Estados Unidos. Véase Cordero Gordillo (2008).

33 En efecto, la Sentencia del Tribunal Superior de Justicia de Cataluña de 23 de junio de 2011 consideró la discriminación por asociación en el despido de una trabajadora que solicitó una ayuda prevista en el convenio colectivo para su cónyuge discapacitado. Y la Sentencia del Tribunal Superior de Justicia de Andalucía de 9 de noviembre de 2017 reconoce el despido de una trabajadora con hijo discapacitado.

34 En el caso Guberina contra Croacia, de 12 de septiembre de 2016, el Tribunal considera que el supuesto trato discriminatorio del demandante a causa de la discapacidad de su hijo [...] es una forma de discriminación basada en la discapacidad contemplada en el artículo 14 de la Convención. 
en el que este reconoce por primera vez esta causa discriminatoria. Se trata de la STEDH en el asunto B.S. c. España, de 24 de julio de 2012; mientras que el TC español había inadmitido el amparo por no encontrarle especial trascendencia constitucional (se trataba de una mujer negra, nigeriana, que ejercía la prostitución). Aunque, como advierte Ruth Abril (2013: 316), la sentencia tiene la virtualidad de introducir, por primera vez, el concepto de discriminación múltiple, pero ni desarrolla su contenido, ni su alcance, ni sus consecuencias.

La relevancia de su reconocimiento no es baladí, pues sus consecuencias jurídicas son importantes, ya que puede conducir a que la cuantía de la indemnización por discriminación múltiple sea mayor que la unicausal.

Más recientemente, el Tribunal Europeo de Derechos Humanos también se ha pronunciado en la Sentencia de 25 de julio de 2017 (caso Carvalho Pinto de Sousa), reconociendo una discriminación por razón de sexo y también por razón de edad (discriminación múltiple), derivada de estereotipos de género y edad, lo que permite la acumulabilidad de distintas causas de discriminación.

Nuevamente, el TEDH no se adentra en el concepto de discriminación múltiple, pero la reconoce, que ya es un paso significativo. Y ello a diferencia del TJUE, «que nunca ha admitido el concepto de discriminación múltiple ni sus eventuales consecuencias jurídicas» ${ }^{35}$.

\section{MEDIDAS PATERNALISTAS FALSAMENTE PROTECTORAS}

El Tribunal también ha considerado discriminatorias las medidas paternalista y protectoras que, aunque aparentemente ventajosas, se basan en la debilidad de la mujer, y en la práctica perpetúan la propia posición de inferioridad social de la población femenina.

Elimina del ordenamiento normas que, aunque históricamente respondieran a una finalidad de protección de la mujer como sujeto fisiológicamente más débil, suponen refrendar o reforzar una división sexista de trabajos y funciones mediante la imposición a las mujeres de límites aparentemente ventajosos pero que le suponen una traba para su acceso al mercado de trabajo ${ }^{36}$.

35 Lousada Arochena (2019: 47), «aunque, ciertamente, una discriminación puede basarse en varios de los motivos contemplados en el artículo 1 de la Directiva 2000/78», no existe, sin embargo, ninguna nueva categoría de discriminación resultante de la combinación de algunos de esos motivos, como la orientación sexual y la edad, que pueda concurrir cuando no se haya constatado una discriminación en razón de dichos motivos considerados por separado.

36 STC 229/1992, de 14 de diciembre (trabajo de la mujer en la mina). El Tribunal, en varias de sus sentencias, declara que estas medidas son discriminatorias; especialmente 


\section{ERRADICAR LA DISCRIMINACIÓN MEDIANTE UN DERECHO NIVELADOR Y REPARADOR}

La igualdad sustancial, como ha afirmado el Tribunal Constitucional, es un «elemento definidor de la noción de ciudadanía» (STC 59/2008); de ahí que, en el marco de un Estado social y democrático de derecho, esta se erija en uno de los ejes fundamentadores del mismo.

En esta dirección, el Tribunal Europeo de Derechos Humanos ha reiterado, en diversas ocasiones, que el progreso en la igualdad de sexos es un fin esencial para los Estados miembros del Consejo de Europa, reconociendo en la Sentencia dictada en el caso Thlimmenos contra Grecia, de 6 de abril de 2000, que el derecho a la no discriminación es también transgredido cuando, sin justificación objetiva y razonable, los Estados no aplican un trato diferente a personas cuyas situaciones son sensiblemente diferentes ${ }^{37}$. Igualmente, a la luz del derecho europeo, que ha sido receptor por excelencia en Europa de las medidas de derecho antidiscriminatorio, el Tribunal de Justicia de Luxemburgo remarca la necesidad de la adopción de acciones positivas en la sentencia de 6 de julio de 2000 (asunto Abrahamsson, Anderson y Fogelqvist) al reconocer que:

[...] las normas jurídicas existentes sobre igualdad de trato, que tienen por objeto conceder derechos a los individuos, son insuficientes para eliminar toda forma de desigualdad de hecho si, paralelamente, no se emprenden acciones, por parte de los Gobiernos, de los interlocutores sociales y otros organismos competentes, tendentes a compensar los efectos perjudiciales que resultan, para las mujeres en activo, de actitudes, de comportamientos y de estructuras de la sociedad.

La consecución de la igualdad real y efectiva demanda la adopción de medidas que nivelen las situaciones de desequilibrio. Este es, pues, el fundamento de las denominadas medidas de derecho antidiscriminatorio. Medidas que no son neutras, sino que se traducen en una reparación de lo desigual para reequilibrar.

\section{EL DERECHO ANTIDISCRIMINATORIO COMO EXIGENCIA DE LA IGUALDAD SUSTANCIAL}

En efecto, la consecución del objetivo igualatorio entre hombres y mujeres permite y demanda la adopción de medidas reequilibradoras de

significativo es el caso de la Sentencia 216/1991, de 14 de noviembre, sobre la inadmisión de la mujer a las pruebas para el ingreso en la Academia General del Aire.

37 Un estudio más detallado de la Jurisprudencia del Tribunal Europeo lo hace Carmona Cuenca (2018). 
situaciones sociales discriminatorias preexistentes para lograr una sustancial y efectiva equiparación entre las mujeres, socialmente desfavorecidas, y los hombres, a fin de asegurar el goce efectivo del derecho a la igualdad por parte de la mujer ${ }^{38}$. La consecución del mandato igualitario se supedita, pues, a la adopción de medidas que tengan como objetivo nivelar las situaciones de desequilibrio con el fin de superarlas.

Para combatirlas nacen las medidas de derecho antidiscriminatorio ${ }^{39}$, que se caracterizan por ser grupales, ya que lo que el derecho antidiscriminatorio intenta paliar es la situación de injusticia que sufren quienes pertenecen a un determinado grupo frente a quienes pertenecen a otro (Barrere, 1997). Además, solo se justifican si son temporales, esto es, hasta que la situación de desequilibrio que pretenden corregir se compense.

Estas medidas han ido adoptando diversas modalidades ${ }^{40}$.

\subsection{Las acciones positivas}

Las más características son las acciones positivas, situándose su origen en Estados Unidos tras el final de la Segunda Guerra Mundial. Origen que está profundamente ligado a las reivindicaciones de la población de color y que, posteriormente, en los años sesenta, estas políticas de igualdad se extenderán hacia otros rasgos como el sexo, la religión y el origen nacional y terminarán dando cobertura a la edad, la orientación sexual, la discapacidad, al estatus marital y a la riqueza (Barrere, 2001) ${ }^{41}$.

El Tribunal Constitucional español ha aceptado la plena licitud constitucional de las medidas de acción positiva para corregir situaciones desfavorables concediendo determinadas ventajas a los sectores desfavorecidos. Esto es, las acciones positivas son todas aquellas medidas de impulso o de favorecimiento a un colectivo que se encuentra en desventaja desde el punto de partida (plus económico para guardería para las madres que trabajan, STC128/1987). En síntesis, estamos ante medidas que tienen como objetivo igualar las situaciones de desequilibrio real, ofreciendo un trato favorable y justificado a un colectivo que se encuentra desfavorecido desde el punto de partida en la realidad.

La diferente situación de partida de la mujer la reconoce el Tribunal cuando afirma que, puesto que la realidad social (que no puede, a este respecto, ignorarse si no se quiere dejar vacíos de contenido los preceptos constitucionales

\footnotetext{
38 SSTC 128/1987, de 16 de julio y 19/1989, de 31 de enero.

39 Un estudio pormenorizado puede verse en Esparza-Reyes y Díaz Revorio (2019).

40 Véanse Ruiz Miguel (1996); Giménez Gluck (1999).

41 Estas reciben cobertura legislativa en 1964 en la Ley de Derechos Civiles, y luego la Ley de Igualdad de Oportunidades en el Empleo de 1972. Gómez Orfanel (2008: 380).
} 
contrarios a la discriminación de la mujer) es claramente muy distante de una situación de igualdad, los poderes públicos tienen la obligación de remediarla. En consecuencia, las acciones positivas no pueden considerarse vulneradoras del principio de igualdad, aun cuando establezcan para ellas un trato más favorable, pues se trata de dar tratamiento distinto a situaciones efectivamente distintas.

La conexión entre igualdad material y acciones positivas la advierte con claridad el Tribunal al anudarlas. Trascribimos por su especial relieve las palabras del Tribunal cuando afirma que:

[...] no podrá reputarse de discriminatoria y constitucionalmente prohibida — antes al contrario - la acción de favorecimiento, siquiera temporal, que aquellos poderes emprendan en beneficio de determinados colectivos, históricamente preteridos y marginados, a fin de que, mediante un trato especial más favorable, vean suavizada o compensada su situación de desigualdad sustancial (STC 216/1991, de 14 de noviembre).

\subsection{La discriminación inversa}

Conocida en Europa como discriminación positiva, tiene el mismo objeto que la acción positiva: la eliminación de las desigualdades y la consecución de la igualdad entre hombre y mujeres; pero la discriminación positiva es una modalidad más incisiva, que adopta diversas modalidades: sistema de cuotas (reserva rígida de un número o porcentaje mínimo garantizado de plazas) y tratos preferentes (atribución de puntos o calificaciones especiales a los grupos a los que se quiere favorecer). A diferencia de las acciones positivas, la discriminación inversa sí que causa un beneficio para unos y un perjuicio a aquellos sujetos que quedan excluidos, ya que se da, por ejemplo, en casos de escasez de puestos de trabajo, plazas, listas (Rey, 2017: 144). Ahora bien, esto no determina su inconstitucionalidad, pues con fundamentación razonable y cumpliendo determinadas exigencias gozan de encaje constitucional.

El Tribunal ha venido a reconocer la constitucionalidad de las cuotas en las listas electorales ${ }^{42}$, prevista tanto en la legislación estatal como en la de algunas comunidades autónomas. La STC 40/2011, de 31 de marzo ${ }^{43}$ condensa la

42 La STC 12/2008, de 29 de enero, en relación con el art. 44 bis y concordantes de la Ley Orgánica 5/1985, del régimen electoral general, redactados por la disposición adicional segunda de la Ley Orgánica 3/2007, para la igualdad efectiva de mujeres y hombres (Belda Pérez-Pedrero, 2006).

43 Que resuelve el Recurso de Inconstitucionalidad interpuesto por sesenta y un diputados del Grupo Parlamentario Popular del Congreso frente al art. 23 de la Ley 1/1986, de 2 de enero, electoral de Andalucía, en la redacción dada por la Ley 5/2005, de 8 de 
posición mantenida en los diversos pronunciamientos. En efecto, ante el cuestionamiento de estas medidas, el Tribunal Constitucional, partiendo de que la libertad de los partidos y agrupaciones de electores para confeccionar y presentar candidaturas no es un derecho fundamental, «sino una atribución, implícita en la Constitución (art. $6 \mathrm{CE}$ ), conferida por el legislador, que puede ser limitada en atención a otros valores y bienes constitucionales protegidos", estima que no cabe apreciar que puedan suponer una infracción de la igualdad de los ciudadanos, sino que, por el contrario, es justamente esa igualdad la que la propia medida asegura.

Exigir de los partidos políticos que cumplan con su condición constitucional de instrumento para la participación política, mediante una integración de sus candidaturas que permita la participación equilibrada de ambos sexos, supone servirse de los partidos para hacer realidad la efectividad en el disfrute de los derechos exigida por el art. 9.2 CE (igualdad real y efectiva). Puesto que es legítimo el fin de la consecución de una igualdad efectiva en el terreno de la participación política, resulta razonable el régimen instrumentado que se limita a exigir una composición radicalmente igualitaria ente hombres y mujeres. Además, entiende que este requisito de la paridad de sexos en las candidaturas electorales no perjudica a la unidad del pueblo soberano, ya que, aunque la voluntad del pueblo español se expresa a través del cuerpo electoral, este no se confunde con el titular de la soberanía.

\section{Bibliografía}

Abril Stoffel, R. (2013). El reconocimiento judicial de la discriminación múltiple en el ámbito de europeo. Revista de Derecho Comunitario, 44, 309-326.

Balaguer Callejón, Ma L. (1991). Igualdad y Discriminación Sexual en la Jurisprudencia del TC. Revista de Derecho Político, 33, 99-124. Disponible en: https:// doi.org/10.5944/rdp.33.1991.8504.

Barrere Unzueta, M. A. (1997). Discriminación, derecho antidiscriminatorio y acción positiva en favor de las mujeres. Madrid: Civitas.

- (2001). Problemas del Derecho Antidiscriminatorio: subordinación versus discriminación y acción positiva versus igualdad de oportunidades. Revista Vasca de Administración Pública, 60, 121-139.

abril, que prevé la obligatoria colación alternativa de hombre-mujer para la presentación de la lista de candidatos para el Parlamento andaluz. Introducía las denominadas listas cremallera. Y la Sentencia 13/2009, de 19 de enero, resuelve el recurso de la Ley del Parlamento Vasco 4/2005, de 18 de febrero, para la igualdad de mujeres y hombres. 
Belda Pérez-Pedrero, E. (2006). La paridad electoral como finalidad disociada de las acciones positivas en favor de un sexo: comentario legislativo de interés autonómico. Parlamento y Constitución. Anuario, 10, 181-198.

Carmona Cuenca, E. (2018). Los principales hitos jurisprudenciales del Tribunal Europeo de Derechos Humanos en materia de igualdad de género. Teoría y Realidad Constitucional, 42, 311-334. Disponible en: https://doi.org/10.5944/ trc.42.2018.23635.

Cordero Gordillo, V. (2008). Discriminación por asociación con una persona con discapacidad. Comentario de la STJCE de 17 de julio de 2008, Coleman, C-303/06. Revista de Derecho Social, 4, 49-161.

Elosegui, M. (1998). Igualdad y diferencia hombre-mujer según el Tribunal Constitucional español. Revista Vasca de Administración Pública, 52, 145-194.

Esparza-Reyes, E. y Díaz Revorio, F. J. (2019). Los mecanismos jurídicos de lucha contra la discriminación: aportaciones para la configuración del derecho antidiscriminatorio. Revista de Derecho Politico, 105, 57-79. Disponible en: https:// doi.org/10.5944/rdp.105.2019.25268.

Giménez Gluck, D. (1999). Una manifestación polémica del principio de igualdad: acciones positivas moderadas y medidas de discriminación inversa. Valencia: Tirant lo Blanch.

Gómez Orfanel, G. (2008). Acciones positivas a favor de la mujer en España: doctrina, jurisprudencia y legislación. Anuario de Derechos Humanos. Nueva Época, 9, 379-402.

González Cussac, J. L. (2009). Aplicación de las figuras penales de violencia de género tras la STC 59/2008.

Larrauri Pijoan, E. (2009). Igualdad y violencia de género. Comentario a la STC 59/2008. InDret, 1.

López Guerra, L. (2000). Igualdad, no discriminación y acción positiva en la Constitución de 1978. En VVAA, Mujer y Constitución en España. Madrid: Centro de Estudios Políticos y Constitucionales.

López Pelegrín, C. (2009). Amenazas, Coacciones y Violencia de género. En E. Núnez Castaño (dir.), Estudios sobre la tutela penal de la violencia de género. Valencia: Tirant lo Blanch.

Lousada Arochena, J. F. (2015). Jurisprudencia española sobre igualdad retributiva entre mujeres y hombres. Nueva Revista Española de Derecho del Trabajo, 181, 49-68.

- (2019). Encuentros y desencuentros entre el TEDH y el TJUE en materia de igualdad de género según el TJUE. Femeris, 4 (2), 39-49. Disponible en: https://doi.org/10.20318/femeris.2019.4764.

Navarro Nieto, F. (2015). El principio de igualdad y no discriminación en la reciente jurisprudencia comunitaria. Temas laborales, 130, 83-134.

Polaino-Orts, M. (2008). La legitimación constitucional de un Derecho penal sui generis del enemigo frente a la agresión a la mujer. Comentario a la STC 59/2008, de 14 de mayo. InDret, 3. 
Queralt Jiménez, J. J. (2006). La última respuesta penal a la violencia de género. La Ley, 6420.

Rey Martínez, F. (2004). El derecho fundamental a no ser discriminado por razón de sexo. En AA.VV. La discriminación por razón de sexo tras 25 años de la Constitución española, Madrid: Consejo General del Poder Judicial.

- (2017). Igualdad y prohibición de discriminación: de 1978 a 2018. Revista de Derecho Político, 100, 125-171. Disponible en: https://doi.org/10.5944/ rdp.100.2017.20685.

- (2000). Principales problemas jurídico-constitucionales que afectan a las mujeres en las relaciones de trabajo. En Mujeres y Constitución (pp. 431-466). Madrid: Centro de Estudios Políticos y Constitucionales.

Ridaura Martínez, Ma J. (2018). El sentido actual de la Ley Orgánica de medidas de protección integral contra la violencia de género. En M. Martín Sánchez (dir.). Estudio Integral de la Violencia de Género: un análisis teórico-práctico desde el Derecho y las Ciencias Sociales (pp. 137-164). Valencia: Tirant lo Blanch.

Rodríguez Piñero, M. (1992). Igualdad entre los sexos y discriminación de la mujer. Relaciones Laborales, 2, 10-17.

Rodríguez Piñero, M. y Fernández López, Ma F. (1986). Igualdad y Discriminación. Madrid: Tecnos.

Rubio Llorente, F. (1991). La igualdad en la jurisprudencia del Tribunal Constitucional. Revista Española de Derecho Constitucional, 31, 9-36.

- (1995). Derechos fundamentales y principios constitucionales. Barcelona: Ariel.

Ruiz Miguel, A. (1996). La discriminación inversa y el caso Kalanke. Doxa: Cuadernos de filosofía del Derecho, 19, 123-140. Disponible en: https://doi.org/10.14198/ DOXA1996.19.07.

Serra Cristóbal, R. (2004). La discriminación indirecta por razón de sexo. En M. J. Ridaura Martínez y M. Aznar Gómez (coords.). Discriminación versus diferenciación: especial referencia a la problemática de la mujer (pp. 365-398). Valencia: Tirant lo Blanch.

- (2015). La discriminación múltiple, ¿un nuevo enfoque sobre la igualdad? En J. V. Gimeno Sendra y M. T. Regueiro García (eds.). Nuevas tendencias en la interpretación de los derechos fundamentales (pp. 133-146). Madrid: Universitas.

Solozábal Echevarría, J. J. (1998). Principialismo y orden constitucional. Anuario de la Facultad de Derecho de la Universidad Autónoma de Madrid, 2, 199-225. 